\title{
E-cigarette use among Canadian

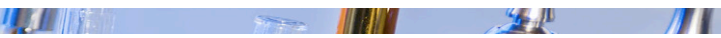

Youth: A review of the literature

using an interdisciplinary lens

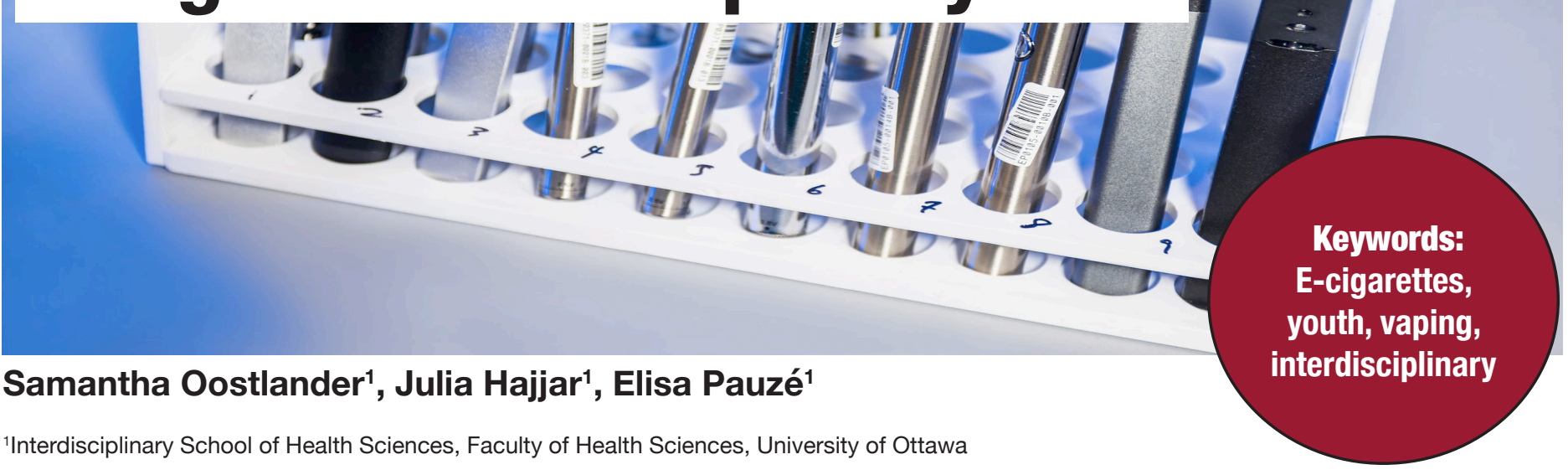

\section{ABSTRACT}

Objective. The increasing use of e-cigarettes among Canadian youth is a concerning population health issue. Vaping, the act of using an e-cigarette, was initially marketed as a healthier alternative to smoking traditional cigarettes, however its use has unintended, negative consequences on its users. One of the most concerning consequences is the presence of "e-cigarette, or vaping, product use associated lung injury" (EVALI) which has led to several hospitalizations. Youth are particularly affected by these negative consequences. This is likely a result of both exposure to marketing, which is a well-established determinant of youth behavior, as well as inadequate public policy. The purpose of this paper is to present a review of the current literature surrounding the issue of e-cigarette use among youth from an interdisciplinary perspective. Method. A narrative review was conducted to summarize the state of e-cigarette use among young Canadians and conceptualize this problem from the perspective of public policy, biomedicine, health economics and education.

Results: The results of this review are a summary of the current state of the literature framed using an interdisciplinary perspective. Recommendations for how these interdisciplinary perspectives can be brought together to provide effective solutions for this population health issue are provided.

Conclusion: Identifying and understanding this problem through an interdisciplinary approach will broaden students, health care professionals, and researchers' perspectives by promoting a holistic understanding of how this issue is impacting multiple systems in Canadian society.

\section{RÉSUMÉ}

Objectifs. L'utilisation croissante de la cigarette électronique chez les jeunes Canadiens est un problème de santé publique préoccupant. « Vaping ", l'acte d'utiliser une cigarette électronique, a été initialement commercialisé comme une alternative plus saine aux cigarettes traditionnelles. Cependant, son utilisation a des conséquences négatives non intentionnelles sur ses consommateurs. L'une des conséquences les plus inquiétantes est la présence de "lésions pulmonaires associées à l'utilisation des cigarettes électroniques, ou vaporisation de produit" (EVALI), qui a entraîné plusieurs hospitalisations. Les jeunes sont particulièrement touchés par ces conséquences négatives. Cela est probablement dû à la fois à l'exposition au marketing, qui est un déterminant bien établi du comportement des jeunes, et à une politique publique inadéquate. L'objectif de cet article est de présenter une revue de la littérature actuelle sur la question de l'utilisation de la cigarette électronique chez les jeunes tout en adoptant une perspective interdisciplinaire.

Méthodes. Une analyse narrative a été réalisée afin de résumer l'état de l'utilisation de la cigarette électronique chez les jeunes Canadiens et de conceptualiser ce problème du point de vue des politiques publiques, de la biomédecine, de l'économie de la santé et de l'éducation. Résultats: Les résultats de cette revue sont un résumé de l'état actuel de la littérature, tout en adoptant une perspective interdisciplinaire. Des recommandations sont formulées sur la manière dont ces perspectives interdisciplinaires peuvent être réunies afin d'apporter des solutions efficaces à ce problème de santé publique.

Conclusion. L'identification et la compréhension de ce problème par le biais d'une approche interdisciplinaire permettra d'élargir les perspectives des étudiants, des professionnels de la santé et des chercheurs en favorisant une compréhension holistique de l'impact de cette question sur les multiples systèmes de la société canadienne. 


\section{INTRODUCTION}

The rapid increase in the use of e-cigarettes among Canadian youth has garnered considerable media attention. Electronic cigarettes, or e-cigarettes, are battery powered devices that heat an enclosed liquid into a vapour that is then inhaled by its user (1). The aerosolized liquid, also called e-juice or e-liquid, typically contains a solvent, often propylene glycol and/or glycerin, as well as nicotine and flavorings (1). Vaping, the act of using an e-cigarette, has been acknowledged as a healthier alternative to smoking traditional cigarettes (2). Thus, many have argued in favour of promoting e-cigarette use among smokers to reduce tobacco-related harms and to aid in smoking cessation $(3,4)$. Despite its possible benefits for smokers, the wider availability of e-cigarettes in the Canadian market has raised concerns over its use among non-smokers, particularly youth. The nicotine content of e-cigarettes is worrisome as this substance is very addictive and has detrimental effects on the developing brains of adolescents (5). In addition to delivering nicotine in quantities similar to that of traditional cigarettes, newer e-cigarettes that use benzoic acid and nicotine salt allow nicotine to be delivered more enjoyably, causing a less harsh sensation in users' throat and mouth (6). This may in turn allow for deeper inhalation of vapour and more effective delivery of nicotine (6). It may also increase the appeal of e-cigarettes among young people (5).

The use of e-cigarettes among youth likely resulted from exposure to marketing, a well-known determinant of youth smoking (7-9). Television, celebrity endorsements and social media all have a powerful influence over the behaviours of youth and are being utilized to promote e-cigarettes. For example, at the Sundance Film Festival in 2018, Juul, a popular e-cigarette brand, gifted guests with dollar bundles of its popular e-cigarettes, and celebrities posed for photos in front of a Juul advertisement backdrop (10). E-cigarettes have also been promoted by e-cigarette retailers and brands, through popular gaming and social media apps including PokemonGo, Twitter, Snapchat, Instagram, YouTube and Facebook (11-15). Little research has examined the commercial promotion of e-cigarettes in Canada (16-18). Therefore, it is unknown how much of the current literature on this topic is reflective of the Canadian context. However, we do know that most Canadian adolescents are exposed to e-cigarette promotions. In 2017, 74\% of the Canadian youth aged $16-19$ years old, reported having seen an advertisement for vaping products in the previous month, most often on social media and at temporary vending locations, and $36 \%$ of those exposed considered these e-cigarette promotions to be appealing (16).

In May 2018, the sale of e-cigarettes was legalized in Canada (19). Large e-cigarette companies, some now affiliated with multinational tobacco corporations, have moved into the Canadian market and anecdotal evidence suggests that the promotion of e-cigarettes has subsequently increased (20-23). Public health advocates, physicians and school boards have been sounding the alarm about the increased access, use and harmful effects of e-cigarettes among youth and have called for greater control over this product $(20,24-25)$. This paper presents a review of the issue of e-cigarette use among youth from an interdisciplinary perspective. We explore this problem from the perspective of public policy, biomedicine, health economics and education. We also discuss how this problem can be further understood through research, field epidemiology and engagement with various stakeholders. By presenting this issue using an interdisciplinary approach we aim to broaden students, health care professionals, and researchers' perspectives, and provide a holistic view of how this relevant issue is impacting Canadian society.

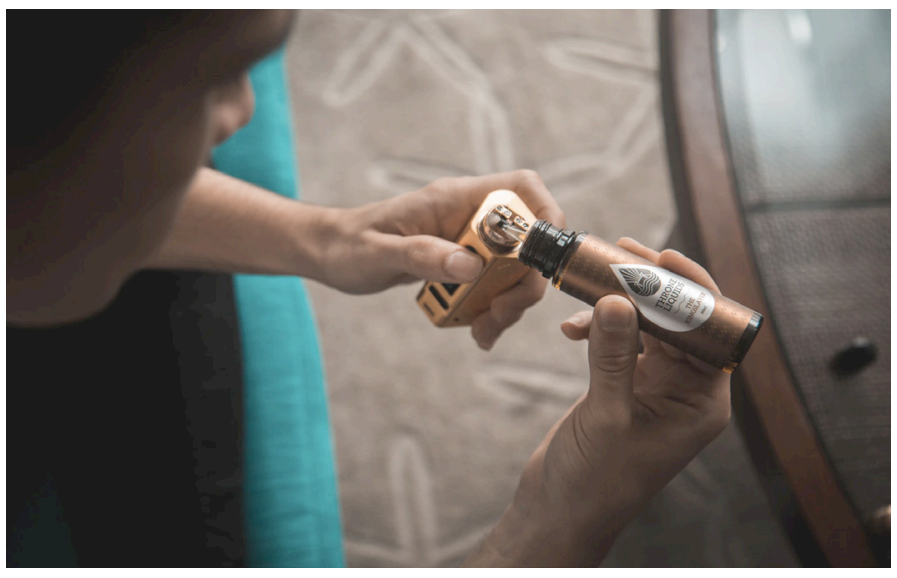

\section{METHODS}

A narrative review was conducted to summarize the current state of the literature on e-cigarette use among Canadian youth and explore this problem from the perspective of public policy, biomedicine, health economics and education. A literature search was conducted using PubMed, Medline, Scopus, Google scholar and Google. As this is an emerging population health issue, both peer- 
reviewed articles and grey literature such as news media articles, government websites, and government funded reports were included. A search was conducted using the terms: e-cigarette, vaping, Canada and youth. A total of 75 articles were included in this review and framed using an interdisciplinary perspective.

\section{RESULTS}

\section{Public policy perspective}

The increased use of e-cigarettes among youth can be understood as a political problem requiring better public policy. E-cigarettes containing nicotine were legalized and formally regulated by the Canadian federal government in 2018 when amendments to the Tobacco and the Non-smokers' Health Act were enacted (19). This law, now called the Tobacco and Vaping Product Act (TVPA), allowed Health Canada to regulate vaping products including their manufacturing, sale, labelling and marketing (19). Recognizing the need to protect youth, the TVPA endeavored to restrict promotional activities that appeal to this demographic. Current regulations prohibit sponsorship, branded merchandise, lifestyle marketing, testimonials and endorsements, the depiction of a person or cartoon character, the restriction of certain flavours such as candy, as well as any other form of advertising believed, "on reasonable grounds", to appeal to young people (19, 26). Contrary to the federal restrictions that apply to tobacco products, the online retailing of e-cigarettes and point-of-sale advertising are permitted unless restricted at the provincial level. Laws and regulations that restrict the sale and advertising of e-cigarettes to youth vary by province. While most provinces had enacted laws setting the minimum age for purchasing e-cigarettes at 18 or 19 years old before the introduction of the TVPA, others, such as Alberta, Saskatchewan, and the territories, had not yet done so (27). In many provinces, product displays and prominent advertising were prohibited in stores accessible to youth (27). Others without such restrictions when the TVPA was introduced, like Ontario and Alberta, saw advertising of e-cigarettes proliferate inside and outside convenience stores and gas stations (20-21, 23).

Alarmingly, the use of e-cigarettes has increased since the introduction of the TVPA and in spite of provincial legislation. The proportion of Canadian youth aged 16-19 years old who reported vaping in the past 30 days had more than doubled within two years; from $8.4 \%$ in July-
August 2017 to 17.8\% in August-September 2019 (28). The frequency of vaping also increased; the prevalence of youth that vaped 20 days or more in the last month reached $5.7 \%$ in 2019, up from $1.8 \%$ observed two years prior (29). Many stakeholders and parents have raised their concern over youth's uptake of e-cigarettes, particularly the JUUL brand whose standard product contains upwards of 50 milligrams of nicotine per millilitre, which is higher than other e-cigarette brands (30-31). While the company denies that it markets to Canadian youth, some medical professionals propose that its enticing flavours, sleek USB-like design, and affordability are all factors intended to appeal to this demographic (32). In 2018, $10.8 \%$ of Canadian youth aged 16-19 years old who had vaped in the past 30 days reported JUUL as their habitual brand, up from 0\% in 2017 (29). This increase is significant given that JUUL had only been available in Canada for one month at the time of the survey (29).

In response to these worrisome trends and calls for tighter regulations, Health Canada signaled its intent to review the TVPA and initiated public consultations in 2019. Changes under consideration include further restrictions on advertising content and limiting the placement of e-cigarette advertisements in retail environments, public places, and print media as well as before, during and after child/youth television programming (33). Limits on nicotine content, regulation of e-cigarette design features, the prohibition of additional flavours and online sales are also being considered (19). In parallel, provinces and territories that have not yet regulated the sale and advertising of e-cigarettes have recently indicated their intention to do so (27). The increasing use of e-cigarettes among youth has likely arisen, in part, due to inadequate policies that failed to prevent youth from accessing e-cigarettes and protect them from the influence of marketing.

\section{Biomedical Research Perspective}

The increased use of e-cigarettes has led to the increased incidence of "e-cigarette, or vaping, product use associated lung injury" (EVALI) in hospitals across North America (34). Individuals entering the hospital with these lung-related ailments are typically cited as experiencing severe cough, fever, chest pain, abdominal pain, vomiting, and shortness of breath (35-36). According to Health Canada, an EVALI case must also have the following criteria: a negative result for tests of lung infection or infection that is not the sole 
cause of the presenting symptoms, lung abnormalities detected via diagnostic imaging, history of e-cigarette use in the 90 days prior to symptom onset and no evidence to support another possible diagnosis (36). This issue is of great concern to healthcare professionals, who are not yet equipped with best practice guidelines for the treatment of EVALI. As a result, increased pressure is being placed on biomedical researchers to determine EVALI's underlying pathophysiology to guide future medical interventions.

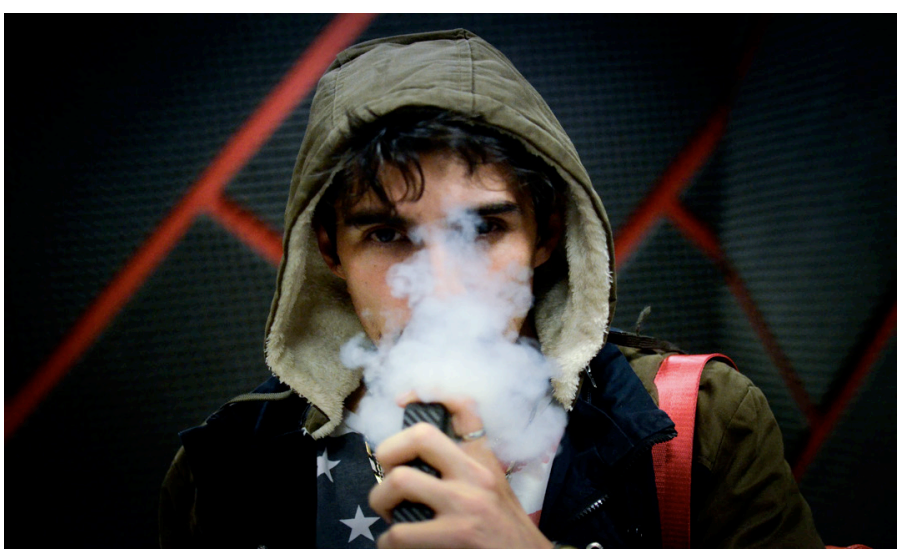

Literature examining the mechanisms underlying EVALI is in its infancy. A study conducted by Blount et al (2019) is one of the most recent contributions to understanding how e-cigarettes impact biological function. In this study, fluid samples were taken from the lungs of 29 individuals with EVALI. All samples contained Vitamin E acetate, 23 contained tetrahydrocannabinol (THC) or its metabolites and 16 contained nicotine metabolites (37). Vitamin E acetate, the esterified and more stable form of Vitamin E, is often added to food, pharmaceutical and supplement products, where it is absorbed into the body through oral and transdermal routes (38). While ingestion and dermal application are not typically associated with adverse health effects, inhalation of vitamin $E$ acetate can interfere with normal lung functioning (39). When inhaled, the aliphatic tail of vitamin $E$ acetate anchors itself into pulmonary surfactants which are a mixture of lipids and proteins that play a role in lowering the surface tension within alveoli cells (site of gas exchange in the lungs) (40-41). When the phospholipids are exposed to vitamin E acetate, they transition from a gel to a liquid crystalline structure which can impair respiration by impacting the surfactants' ability to control surface tension (40-41). In the case of vaping, the vitamin $E$ acetate is heated up in the device prior to inhalation which can cause the acetate group to split off from the main molecule to create ketene, a reactive compound that has the potential to be a lung irritant depending upon the concentration inhaled $(39,42)$. It has been proposed that vitamin $\mathrm{E}$ acetate is being added to illicit THC cartridges which may further complicate the mechanism by which e-cigarette use interferes with normal lung functioning (43). Further studies are required before confirming a causal link (37). Additionally, other mechanisms leading to the negative effects of e-cigarette use may have yet to be identified.

The use of computed tomography (CT) and radiographs are techniques which can also offer unique insights into what areas of the lungs are affected by EVALI. Two main imaging patterns are common on the scans of those presenting with EVALI: basilar-predominant consolidation and ground-glass opacity (44-45). Basilar-predominant consolidation refers to tissue at the base of the lungs that is filled with liquid instead of air (44). Ground-glass opacity refers to partial areas of the lungs that are filled with liquid instead of air and indicates an interstitial thickening or partial collapse of the alveoli (46). Interestingly, in some individuals these anomalies have reduced after cessation of e-cigarette use and glucocorticoid therapy, which reduces the inflammatory response $(44,45-48)$. Antimicrobial and antiviral therapies are also being considered for treatment, as symptoms of EVALI overlap with that of pneumonia and influenza (47-48).

While the long-term effects of EVALI are not fully understood, in vitro studies using human epithelial cells show that chronic exposure to toxic components of e-cigarette vape (propylene glycol, glycerin, and nicotine) disrupt airway epithelium which can lead to damage in multiple organs (49). Similarly, in vivo studies using mice show that chronic exposure to these toxic components leads to increased inflammation, organ damage, and cardiorenal and hepatic disease (50). Altered organ physiology may in turn lead to a reduced ability to fight off infectious diseases such as influenza (51). While the chronic impact of e-cigarette use in humans requires further exploration, the negative acute effects on lung functioning, such as pulmonary edema and shortness of breath, in previously healthy youth are cause for concern (52). To minimize the potential health hazards related to vaping, the current recommendations provided by the CDC and PHAC are: to avoid initiating the use of e-cigarettes, to stop or avoid e-cigarette use with THC additives for those who continue to use them, and to 
avoid acquiring e-cigarette products from informal and illicit sources $(47,53)$.

In addition to lung-related harms, the nicotine content of e-cigarette poses a particular risk to the developing brain of adolescents which undergo a marked reorganization, particularly in areas related to cognition, executive function, short-term memory, motivated behavior, emotional control and reward processing (5). Notably, studies conducted using animal models have found that adolescents are uniquely vulnerable to nicotine exposure largely due to the immaturity of nicotinic acetylcholine receptors throughout the brain (5). These receptors play a role in regulating the mesolimbic dopamine system by mediating the firing of dopamine neurons in the ventral tegmental area (54). Nicotinic acetylcholine receptors in this area have been previously implicated in studies examining tobacco addition (55). Compared to adults, when exposed to nicotine, adolescent rodents exhibit increased sensitivity to the rewarding effects of nicotine, enhanced locomotor activity and blunted withdrawal symptoms (5658). Perhaps what is of greatest concern is that chronic exposure to nicotine in adolescents has been suggested to have lifelong impacts on serotonergic signalling and result in remodelling of dendrites in areas such as the nucleus accumbens (59-60). This can result in diminished cognitive function, reduced attention span, enhanced impulsivity, and increased anxiety-like and depression-like emotional states in adulthood (61-62). Regardless of the concentration of nicotine present in e-cigarettes, it is clear that even brief exposure to low doses of nicotine can result in long-term changes to adolescent brains (5).

\section{Economic Perspective}

The use of e-cigarettes among youth can be understood as an economic issue burdening the public healthcare system. Although e-cigarettes have existed for more than a decade, an outbreak of EVALI was not announced until 2019, likely as a result of increased use, particularly by the youth demographic (34). As this outbreak is recent and on-going there are no published estimates regarding the cost of e-cigarette use or its economic impact. However, with numerous individuals requiring extensive medical intervention, costs related to EVALI are likely to leave a lasting impact. According to the CDC, as of November 5th $2019,95 \%$ of over 2,000 individuals with EVALI were hospitalized in the United States (63). The median age of those hospitalized was 24 years old, with $77 \%$ being under the age of 35 (63). The public health agency of Canada reported that as of April 7th 2020, there have been 19 vaping-related lung illnesses, however the demographic characteristics of those affected are unknown (64) Individuals experiencing EVALI may require the speciality services of an intensive care unit (ICU) and according to The Canadian Institute for Health Information, an overnight stay in the ICU in 2016 cost approximately $\$ 3,592$; three times higher than a general ward bed $(43,65)$. The use of e-cigarettes will contribute to increased pressure on an already resource-strained health care system and contribute to increased health care costs.

\section{Educational Perspective}

The use of e-cigarettes by youth in schools has also emerged as a behavioral problem in this context. Much like traditional cigarettes, the attitudes of young people towards e-cigarettes is influenced by the opinions and vaping behaviours of friends and family (9). Some young people believe that e-cigarettes are more socially acceptable, and their use is viewed as an expression of social identity (9). Indeed, vaping currently boasts a "cool factor" for youth (9), reminiscent of smoking cigarettes in past decades. As such, peer influence and perceived social norms are likely drivers of e-cigarette use in schools. Action at the provincial and local level have been taken to curb this behaviour. For example, the Smoke-Free Ontario Act has banned vaping on school grounds and within 20 meters of school property since October 2018 (66). In Ottawa, St. Joseph High School has initiated the removal of washroom doors and a $\$ 250$ dollar fine to any student caught vaping inside the school (67). Other school boards throughout Canada have followed suit and have banned vaping on school property (24). Concern regarding the use of e-cigarettes in adolescence is related to the effects of nicotine on the developing brain, particularly the prefrontal cortex, which is involved in the control of attention and executive functioning (68). Exposure to nicotine during adolescence has been shown to compromise emotional and cognitive processing and disrupt working memory (5, $69)$.

Health Canada has been actively involved in mitigating youth vaping practices. At the end of 2018, it launched a vaping prevention public education campaign that targeted youth, parents and other adults (19). As part of 
this campaign, movie theatres were used as a platform to disseminate information to youth about the dangers of vaping, and signs prohibiting smoking/vaping were placed at public venue entrances (19). Interactive teaching sessions in high schools and community centers across Canada are being conducted to cultivate more discussion and awareness around the dangers of vaping (19). Vaping Awareness Kits have also been provided to schools that do not participate in these sessions and includes: posters, "no vaping/no smoking" signs, activity sheets for students, and tip sheets for teachers and parents to increase awareness and support vaping discussions with youth (19).

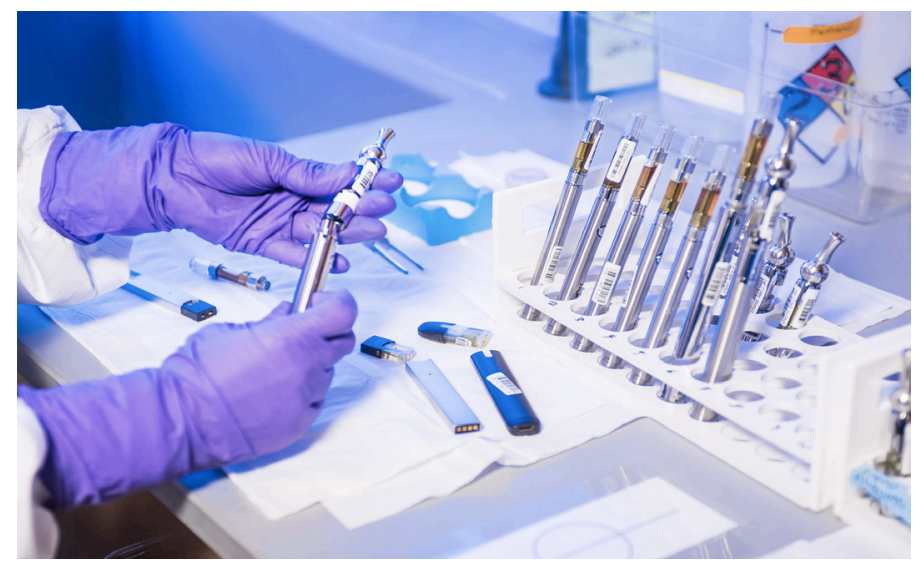

\section{DISCUSSION}

E-cigarette use among youth is a significant population health issue in Canada. The interdisciplinary perspectives presented above helped to conceptualize the current issue by using diverse professional lenses to analyze the context in which this issue emerged. Below we suggest some ways in which interdisciplinary and intersectoral collaboration can help pave the way for effective and sustainable solutions. Given the impact of e-cigarettes on public health, continued monitoring of vaping among youth will be required to understand the scale and evolution of this problem, and its contributing factors. Public consultations regarding the review of the TVPA has allowed stakeholders including members of the general public, academia, municipalities, public health advocates, and health professionals and their associations, to engage with the policy-making process and provide feedback (70). Since the ultimate goal is to protect youth, direct engagement with young individuals is necessary to understand their motives for using e-cigarettes and identify the sources that influence this behavior. Qualitative approaches such as focus groups could provide valuable insights on youth's perception and use of e-cigarettes. Involving youth in the policymaking process would also be a powerful and meaningful way to engage young individuals. Some Canadian youth are already advocating and lobbying for stricter regulation of e-cigarettes (71).

In terms of engaging the health care sector, the Ontario Agency for Health Protection and Promotion Act 2007, requires institutions such as hospitals, long-term care facilities and retirement homes to report disease outbreaks to their local health authority (72), which then work with these institutions to investigate all reports of suspected and confirmed outbreaks (73). In these cases, field epidemiologists are employed to investigate the public health issue and offer guidance in the process of selecting and implementing interventions to lessen and prevent illness/death in a timely manner (74). Field epidemiologists could be deployed to investigate the use of e-cigarettes and the linked EVALI hospitalizations in order to identify the products responsible for this condition. Public health agencies may then disseminate findings in the form of reports and warnings to the public.

Health Canada may serve as a strong ally in partnering with school boards throughout Canada to mitigate the issue of vaping among youth. The Canadian School Board Association has stated that it is seeking assistance from the federal government to enhance educational programs to better educate students about the dangers of vaping (75). Funding assistance from the government would allow school boards to follow through with effective programs, such as a newly introduced physical education program supplemented with a component on the health effects of vaping (75). Engagement within schools is also crucial in moderating the issue of youth vaping. School policy should be reinforced by staff, including the confiscation of vaping products found on school property and the reporting of incidents to by-law, which requires students to pay a $\$ 250$ fine (67). Communication between teaching staff and parents is vital to raise awareness and disseminate information between the school and the home. Providing parents with information on vaping, including how to identify the products and their adverse health effects, is an important way to ensure that parents remain vigilant and aware of their adolescents' behaviours while at home. Cohesion between government legislation, school policy, advertisements and educational promotion will provide more consistent messaging to youth, and will be a more 
effective strategy in mitigating youth vaping.

\section{CONCLUSION}

E-cigarette use among Canadian youth is a concerning population health issue. Vaping was marketed as a healthier alternative to cigarette smoking and promoted as a means to reduce smoking-related harms. However, rather than having a net benefit for public health, it has had unexpected deleterious consequences due to the effects of nicotine, THC, vitamin E acetate and other potentially unknown chemicals. Youth are an overrepresented population currently affected by vaping related consequences, which may have been the result of effective marketing techniques used by e-cigarette companies as well as inadequate public policies. Identifying and understanding this problem through an interdisciplinary approach that engages stakeholders including policy makers, public health agencies, field epidemiologists, biomedical researchers, school boards and youth themselves has the potential to create more effective and sustainable solutions. Partnerships between school boards and governmental bodies can enhance educational resource allocation and align messaging to youth through several platforms.

\section{REFERENCES}

1. Breland A, Soule E, Lopez A, Ramôa C, El-Hellani A Eissenberg T. Electronic cigarettes: What are they and what do they do? Annals of the New York Academy of Sciences. 2017 Jan;1394(1):5 30.

2. National Academies of Sciences, Engineering, and Medicine Public Health Consequences of E-Cigarettes. Washington DC: The National Academies Press. 2018.

3. Etter JF. Should electronic cigarettes be as freely available as tobacco? Yes. BMJ. 2013 June;346:£3845.

4. Hajek P. Electronic cigarettes have a potential for huge public health benefit. BMC Medicine. 2014 Dec;12:225.

5. Yuan M., Cross SJ, Loughlin SE, Leslie FM. Nicotine and the adolescent brain. The Journal of Physiology. 2015 May;593(16):3397 3412.

6. Voos N, Goniewicz ML, Eissenberg T. What is the nicotine delivery profile of electronic cigarettes? Expert opinion on drug delivery. 2019 Nov;16(11):1193-203.

7. US Department of Human Health and Human Services. Preventing Tobacco Use Among Youth and Young Adults: A Report of the Surgeon General. US Department of Human Health and Human Services, National Center for Chronic Disease Prevention and Health Promotion Office on Smoking and Health. Atlanta, (GA), 2012.

8. Lovato C, Linn G, Stead LF, Best A. Impact of tobacco advertising and promotion on increasing adolescent smoking behaviours. Cochrane Database Syst Rev. 2003;(4):CD003439.

9. Amin S, Dunn GA, Laranjo L. Social influence in the uptake and use of electric cigarettes: A systematic review. American Journal of Preventive Medicine. 2020 Jan;58(1):129-141

10. Maloney J, McKay B. Teen Vaping Didn't Cool Juul's Celebrity Push [Internet]. New York (NY): The Wall Street Journal; 2019 Sept 28. Available from: https://www.wsj.com/articles/ teen-vaping-didnt-cool-juuls-celebrity-push-11569643202.

11. Kirkpatrick MG., Cruz TB., Goldenson NI, Allem JP, Chu
$\mathrm{KH}$, Pentz MA, et al. Electronic cigarette retailers use Pokémon Go to market products. Tobacco Control. 2017 Dec;26(e2):e145 e147.

12. Huang J, Kornfield R, Szczypka G, Emery SL. A crosssectional examination of marketing of electronic cigarettes on Twitter. Tobacco Control. 2014 June;23(suppl 3): iii26 iii30.

13. Huang J, Duan Z, Kwok J, Binns A, Vera LE, Kim Y, et al. Vaping versus JUULing: How the extraordinary growth and marketing of JUUL transformed the US retail e-cigarette market. Tobacco Control. 2018 May;28:146-151.

14. Allem JP., Escobedo P, Cruz TB, Unger JB. Vape pen product placement in popular music videos. Addictive Behaviors. 2019 June;93:263 264.

15. Barone T. (2019). Vaping isn't supposed to be marketed to youth. So why do I see 'ads' for it everywhere? [Internet] Toronto (ON): CBC News; 2019 Sept 05. Available from: https://www.cbc.ca/news/canada/montreal/vaping-isn-tsupposed-to-be-marketed-to-youth-1.5264485.

16. 16. Cho YJ, Thrasher JF, Reid JL, Hitchman S, Hammond D. Youth self-reported exposure to and perceptions of vaping advertisements: Findings from the 2017 International Tobacco Control Youth Tobacco and Vaping Survey. Preventive Medicine 2019 Sept;126:105775.

17. Hammond D, White CM, Czoli CD, Martin CL, Magennis $\mathrm{P}$, Shiplo S. Retail availability and marketing of electronic cigarettes in Canada. Canadian Journal of Public Health. 2015 Sep; 106(6):e408-12.

18. Richardson A, Ganz O, Vallone D. Tobacco on the web: surveillance and characterisation of online tobacco and e-cigarette advertising. Tobacco control. 2015 Jul;24(4):3417.

19. Health Canada. Reducing youth access and appeal of vaping products. Consultation on potential regulatory measures [Internet]. Ottawa (ON): Government of Canada; 2019 Apr 11. Available from: https://www.canada.ca/en/health-canada/ programs/consultation-reducing-youth-access-appealvaping-products-potential-regulatory-measures/document. html.

20. Ackerman J, Leader-Post R. Cancer society calling on province to ban promotion, advertising of e-cigarettes [Internet]. Toronto (ON): Regina Leader-Post; 2018 Dec 8. Available from: https://leaderpost.com/news/local-news/ cancer-society-calling-on-province-to-ban-promotionadvertising-of-e-cigarettes.

21. Weeks C. Ontario to allow marketing of vaping products [Internet]. Toronto (ON): The Globe and Mail; 2018 October 18. Available from: https://www.theglobeandmail. com/canada/article-ontario-to-allow-marketing-of-vapingproducts/.

22. CBC News. Advertising restrictions to curb vaping among youth, researchers say [Internet]. Toronto (ON): CBC News; 2019 Aug 27. Available from: https://www.cbc.ca/news/ health/e-cigarette-advertising-1.5260652.

23. Dewhirst T. British American Tobacco (BAT) and retail merchandising: Vype e-cigarette promotion in Ontario, Canada. Tobacco control. 2019 Dec;28(e2):e164-7.

24. Smart A. 'Serious danger': B.C. school districts call for increased regulation of vaping [Internet]. Toronto (ON): CBC News; 2019 Oct 14. Available from https://www. cbc.ca/news/canada/british-columbia/bc-schools-vapingregulation-1.5320721.

25. CBC News. Vapes need same restrictions as tobacco, medical groups tell federal parties [Internet]. Toronto (ON): CBC News; 2019 Sept 19. Available from: https://www.cbc. ca/news/health/vaping-thursday-1.5289485.

26. Government of Canada. Tobacco and Vaping Products Act (S.C. 1997, c.13) [Internet]. Ottawa (ON): Government of Canada; 2019 November 29. Available from: https://lawslois.justice.gc.ca/eng/acts/t-11.5/page-6.html\#h-449596.

27. CBC News. Vaping and e-cigarette regulations across Canada [Internet]. Toronto (ON): CBC News; 2019 Oct 18. Available from: https://www.cbc.ca/news/canada/vapingregulations-1.3812180. 
28. Hammond D, Rynard VL, Reid JL. Changes in Prevalence of Vaping Among Youths in the United States, Canada, and England from 2017 to 2019. JAMA pediatrics. 2020 May; 4:e200901.

29. Hammond, D., Reid, J. L., Rynard, V. L., Fong, G. T., Cummings, K. M., McNeill, A. et al. Prevalence of vaping and smoking among adolescents in Canada, England, and the United States: Repeat national cross-sectional surveys. BMJ. 2019 Jun;365:I2219.

30. Goniewicz ML, Boykan R, Messina CR, Eliscu A, Tolentino J. High exposure to nicotine among adolescents who use Juul and other vape pod systems ('pods'). Tobacco Control. 2019 Sept;28(6):676 677

31. Talih S, Salman R, El-Hage R, Karam E, Karaoghlanian N, El-Hellani A, et al. Characteristics and toxicant emissions of JUUL electronic cigarettes. Tobacco Control. 2019 Feb;28(6):678 680.

32. CBC News. Juul names new CEO, suspends all advertising in U.S.- but no change in Canada [Internet]. Toronto (ON): CBC News; 2019 Sept 25. Available from: https://www.cbc. $\mathrm{ca} / \mathrm{news} / \mathrm{business/juul-ceo-advertising-1.5296394.}$

33. 33. Health Canada. Notice of Intent - Potential Measures to Reduce the Impact of Vaping Products Advertising on Youth and Non-users of Tobacco Products [Internet]. Ottawa (ON): Government of Canada; 2019 Feb 26. Available from: https:// www.canada.ca/en/health-canada/programs/consultationmeasures-reduce-impact-vaping-products-advertisingyouth-non-users-tobacco-products/notice-document.html.

34. Salzman GA, Alqawasma M, Asad H. Vaping Associated Lung Injury (EVALI): An explosive United States epidemic. Missouri Medicine. 2019 Nov;116(6):492-496.

35. Chatham-Stephens K, Roguski K, Jang Y, Cho $P$, Jatlaoui TC, Kabbani S, et al. Characteristics of Hospitalized and Nonhospitalized Patients in a Nationwide Outbreak of E-cigarette, or Vaping, Product Use-Associated Lung Injury-United States, November 2019. MMWR. 2019 Nov;68(46):1076-1080.

36. Government of Canada. Severe lung illness related to vaping [Internet]. Ottawa (ON): Government of Canada; 2019 Nov 29. Available from: https://www.canada.ca/en/public-health/ services/diseases/vaping-pulmonary-illness.html.

37. Blount BC, Karwowski MP, Morel-Espinosa M, Rees J, Sosnoff C, Cowan E, et al. Evaluation of Bronchoalveolar Lavage Fluid from Patients in an Outbreak of E-cigarette, or Vaping, Product Use-Associated Lung Injury-10 States, August-October 2019. MMWR. 2019 Nov;68(45):10401041.

38. 38. Yang Y, McClements, DJ. Vitamin E bioaccessibility: Influence of carrier oil type on digestion and release of emulsified a-tocopherol acetate. Food Chemistry. 2013 Nov;141(1):473-481

39. Blount BC, Karwowski MP, Shields PG, Morel-Espinosa M, Valentin-Blasini L, Gardner $M$ et al. Vitamin E Acetate in Bronchoalveolar-Lavage Fluid Associated with EVALI. New England Journal of Medicine. 2020 Feb;382(8):697-705.

40. Kamal MdA, Raghunathan VA. Modulated phases of phospholipid bilayers induced by tocopherols. Biochimica et Biophysica Acta. 2012 Nov;1818(11):2486 2493.

41. Zuo $Y$, Veldhuizen RAW, Neumann AW, Petersen NO, Possmayer F. Current perspectives in pulmonary surfactant - inhibition, enhancement and evaluation. Biochimica et Biophysica Acta. 2008 Oct;1778(10):1947-1977.

42. Wu D, O'Shea DF. Potential for release of pulmonary toxic ketene from vaping pyrolysis of vitamin $E$ acetate. Proceedings from the national academy of sciences of the United States of America. 2020 Mar;117(12):6349-6355

43. Lewis N, McCaffrey K, Sage K, Cheng CJ, Green J, Goldstein L, et al. E-cigarette Use, or Vaping, Practices and Characteristics Among Persons with Associated Lung InjuryUtah, April-October 2019. MMWR. 2019 Oct;68(42):953956.

44. Henry TS, Kanne JP, Kligerman SJ. Imaging of VapingAssociated Lung Disease. New England Journal of Medicine.
2019 Oct:381(15):1486-1487.

45. Layden JE, Ghinai I, Pray I, Kimball A, Layer M, Tenforde M, et al. Pulmonary IIIness Related to E-Cigarette Use in Illinois and Wisconsin-Preliminary Report. New England Journal of Medicine. 2020 Mar;382(10):903-916

46. Gao JW, Rizzo S, Ma LH, Qiu XY, Warth A, Seki N, et al. Pulmonary ground-glass opacity: Computed tomography features, histopathology and molecular pathology. Translational Lung Cancer Research. 2017 Feb;6(1):68-75.

47. Jatlaoui TC. Update: Interim Guidance for Health Care Providers for Managing Patients with Suspected E-cigarette, or Vaping, Product Use-Associated Lung Injury - United States, November 2019. MMWR. 2019 Nov;68(46):10811086.

48. Siegel DA, Jatlaoui TC, Koumans EH, Kiernan EA, Layer M, Cates JE, et al. Update: Interim Guidance for Health Care Providers Evaluating and Caring for Patients with Suspected E-cigarette, or Vaping, Product Use Associated Lung Injury United States, October 2019. MMWR. 2019 Oct;68(41):919927.

49. Hwang JH, Lyes M, Sladewski K, Enany S, McEachern E, Mathew DP, et al. Electronic cigarette inhalation alters innate immunity and airway cytokines while increasing the virulence of colonizing bacteria. Journal of molecular medicine. 2016 Jun;94(6):667-79.

50. Crotty Alexander LE, Drummond CA, Hepokoski M, Mathew $D$, Moshensky A, Willeford A, et al. Chronic inhalation of e-cigarette vapor containing nicotine disrupts airway barrier function and induces systemic inflammation and multiorgan fibrosis in mice. American Journal of Physiology-Regulatory, Integrative and Comparative Physiology. 2018 Jun; 314(6):R834-R847.

51. Madison MC, Landers CT, Gu BH, Chang CY, Tung HY, You $\mathrm{R}$, et al. Electronic cigarettes disrupt lung lipid homeostasis and innate immunity independent of nicotine. The Journal of clinical investigation. 2019 Oct 1;129(10):4290-4304

52. Gotts JE, Jordt SE, McConnell R, Tarran R. What are the respiratory effects of e-cigarettes? BMJ. 2019 Sep $30 ; 366: 15275$.

53. Government of Canada. Information update - Health Canada warns of potential risk of pulmonary illness associated with vaping products [Internet]. Ottawa (ON): Government of Canada; 2019 Oct 17. Available from: https://healthycanadians.gc.ca/recall-alert-rappel-avis/hcsc/2019/70919a-eng.php.

54. Leslie FM. Multigenerational epigenetic effects of nicotine on lung function. BMC medicine. 2013 Feb 4;11:27.

55. Gotti C, Clementi F. Neuronal nicotinic repceptors: from structure to pathology. Progress in neurobiology. 2004 $\mathrm{Dec} ; 74(6): 363-396$.

56. Cao J, Belluzzi JD, Loughlin SE, Dao JM, Chen Y, Leslie FM. Locomotor and stress responses to nicotine differ in adolescent and adult rats. Pharmacology Biochemistry and Behavior. 2010 Jul;96(1):82-90.

57. Torres OV, Tejeda HA, Natividad LA, O'Dell LE. Enhanced vulnerability to the rewarding effects of nicotine during the adolescent period of development. Pharmacology Biochemistry and Behavior. 2008 Oct;90(4):658-663.

58. O'Dell LE, Bruijnzeel AW, Smith RT, Parsons LH, Merves $\mathrm{ML}$, Goldberger BA, et al. Diminished nicotine withdrawal in adolescent rats: implications for vulnerability to addiction. Psychopharmacology. 2006 Jul;186(4):612-619.

59. Slotkin TA, Card J, Seidler FJ. Nicotine administration in adolescence reprograms the subsequent response to nicotine treatment and withdrawal in adulthood: Sexselective effects on cerebrocortical serotonergic function. Brain research bulletin. 2014 Mar;102:1-8.

60. McDonald CG, Eppolito AK, Brielmaier JM, Smith LN, Bergstrom HC, Lawhead MR, et al. Evidence for elevated nicotine-induced structural plasticity in nucleus accumbens of adolescent rats. Brain research. 2007 Jun;1151:211-218.

61. Counotte DS, Spijker S, Van de Burgwal LH, Hogenboom F, Schoffelmeer AN, De Vries TJ, et al. Long-lasting cognitive 
deficits resulting from adolescent nicotine exposure in rats. Neuropsychopharmacology. 2009 Jan;34(2):299-306.

62. Smith LN, McDonald CG, Bergstrom HC, Brielmaier JM, Eppolito AK, Wheeler TL, et al. Long-term changes in fear conditioning and anxiety-like behavior following nicotine exposure in adult versus adolescent rats. Pharmacology Biochemistry and Behavior. 2006 Sep;85(1):91-97.

63. Centers for Disease Control and Prevention. Outbreak of lung injury associated with the use of e-cigarette, or vaping, products [Internet]. Atlanta (GA): Centers for Disease Control and Prevention; 2019 Nov 21. Available from: https://www. cdc.gov/tobacco/basic_information/e-cigarettes/severelung-disease.html.

64. Government of Canada. Vaping associated lung illnesses [Internet]. Ottawa (ON): Government of Canada; 2020 Apr 16. Available from: https://www.canada.ca/en/public-health/ services/diseases/vaping-pulmonary-illness.html.

65. Canadian Institute for Health Information. Care in Canadian ICUs. Ottawa (ON): Canadian Institute for Health Information; 2016 Aug. 36 p.

66. Cillers, R. Educators scramble to stomp out vaping in schools as teen use is soaring [Internet]. Hamilton (ON): The Hamilton Spectator; 2019 Apr 14. Available from: https://www. thespec.com/news-story/9283416-educators-scramble-tostomp-out-vaping-in-schools-as-teen-use-is-soaring/.

67. McQuigge M. New Health Canada campaign warns youth about risks of vaping [Internet]. Toronto (ON): Global News; 2019 Jan 10. Available from: https://globalnews.ca/ news/4835469/health-canada-vaping-youth/.

68. 68. Goriounova NA, Mansvelder HD. Short-and long-term consequences of nicotine exposure during adolescence for prefrontal cortex neuronal network function. Cold Spring Harbor perspectives in medicine. 2012 Dec 1;2(12):a012120.

69. Mooney-Leber SM, Gould TJ. The long-term cognitive consequences of adolescent exposure to recreational drugs of abuse. Learning \& Memory. 2018 Sep 1;25(9):481-491.

70. Health Canada. Consultation Summary: Notice of Intent Potential Measures to Reduce the Impact of Vaping Products Advertising on Youth and Non-users of Tobacco Products [Internet]. Ottawa (ON): Government of Canada; 2019 Oct 31. Available from : https://www.canada.ca/en/health-canada/ programs/consultation-measures-reduce-impact-vapingproducts-advertising-youth-non-users-tobacco-products/ notice-document/summary.html.

71. Hunter A. Sask. To ban vaping near schools and restrict advertising but allow flavours [Internet]. Toronto (ON): CBC News; 2019 Nov 5. Available from: https://www.cbc.ca/news/ canada/saskatchewan/sask-rules-vaping-1.5348292.

72. Government of Ontario. Ontario Agency for Health Protection and Promotion Act, 2007, S.O. 2007, c. 10, Sched. K [Internet]. Ottawa (ON): Government of Canada; 2019 July. Available from: https://www.ontario.ca/laws/statute/07010/v4

73. Ottawa Public Health. Outbreak reports in Ottawa Healthcare Institutions [Internet]. Ottawa (ON): Ottawa Public Health; n.d. Available from: https://www.ottawapublichealth.ca/en/ professionals-and-partners/outbreak-reports-in-ottawahealthcare-institutions.aspx\#Responsibilities-of-OttawaPublic-Health-OPH.

74. Goodman R, Buehler J, \& Mott J. Defining Field Epidemiology Epidemic Intelligence Service [Internet]. Atlanta (GA): Centers for Disease Control and Prevention; 2019 Sept 24. Available from https://www.cdc.gov/eis/field-epi-manual/ chapters/Defining-Field-Epi.html.

75. CBC News. Solution to vaping should be part of larger mental health strategy: B.C. school trustees [Internet]. Toronto (ON): CBC News; 2019 Oct 30. Available from: https://www. cbc.ca/news/canada/british-columbia/vaping-in-bc-schoolstrustees-ask-for-federal-provincial-aid-1.5340740. 